\title{
Effect of Voltage on the Microstructure and Corrosion Properties of MAO Coatings on Biodegradable ZK60 Mg Alloys
}

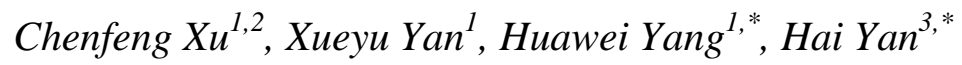 \\ ${ }^{1}$ Department of Stomatology, Affiliated Shanghai Tenth People's Hospital, Tongji University, \\ Shanghai 200072 China \\ ${ }^{2}$ School of Materials Science and Engineering, Jiangsu University of Science and Technology, \\ Zhenjiang 212003 China \\ ${ }^{3}$ Elotouch (Suzhou) Co. Ltd., Suzhou 215009 China \\ *E-mail: yanghuawei@tongji.edu.cn (H. Yang); hai.yen@elotouch.com (H. Yen)
}

doi: $10.20964 / 2018.04 .60$

Received: 10 January 2018 / Accepted: 19 February 2018 / Published: 6 March 2018

\begin{abstract}
In this paper, micro-arc oxidation (MAO) is successfully used to fabricate protective coatings on biodegradable magnesium alloys. The effects of different applied voltages in the MAO process on the phase composition, coating morphology and in vitro corrosion properties of the MAO coatings are investigated by using X-ray diffraction, scanning electron microscopy, electrochemical measurements and immersion tests. The results indicate that the applied voltage has no effect on the phase composition of the coatings, while the thickness and surface morphology of the MAO coatings are significantly affected by the applied voltages in the MAO process. The electrochemical measurements and immersion tests suggest that the ZK60 alloy with the MAO coating fabricated at $350 \mathrm{~V}$ shows the best corrosion resistance in simulated body fluid solutions among all the investigated samples.
\end{abstract}

Keywords: biodegradable magnesium alloys; micro-arc oxidation; EIS; Tafel

\section{FULL TEXT}

(C) 2018 The Authors. Published by ESG (www.electrochemsci.org). This article is an open access article distributed under the terms and conditions of the Creative Commons Attribution license (http://creativecommons.org/licenses/by/4.0/). 